\title{
Plant species richness and functional composition drive overyielding in a six-year grassland experiment
}

\author{
Elisabeth Marquard, ${ }^{1,2,6}$ Alexandra Weigelt, ${ }^{3}$ Vicky M. Temperton,${ }^{1,7}$ Christiane Roscher,${ }^{1}$ \\ Jens Schumacher, ${ }^{1,8}$ Nina Buchmann, ${ }^{4}$ Markus Fischer,${ }^{5}$ Wolfgang W. Weisser, ${ }^{3}$ and Bernhard Schmid ${ }^{2}$ \\ ${ }^{1}$ Max Planck Institute for Biogeochemistry, Hans-Knöll Strasse 10, 07745 Jena, Germany \\ ${ }^{2}$ Institute of Environmental Sciences, University of Zurich, Winterthurerstrasse 190, 8057 Zurich, Switzerland \\ ${ }^{3}$ Institute of Ecology, Friedrich-Schiller University Jena, Dornburger Strasse 159, 07749 Jena, Germany \\ ${ }^{4}$ Institute of Plant Sciences, ETH Zurich, Universitaetsstrasse 2, 8092 Zurich, Switzerland \\ ${ }^{5}$ Institute of Plant Sciences and Oeschger Centre, University of Bern, Altenbergrain 21, 3013 Bern, Switzerland
}

Abstract. Plant diversity has been shown to increase community biomass in experimental communities, but the mechanisms resulting in such positive biodiversity effects have remained largely unknown. We used a large-scale six-year biodiversity experiment near Jena, Germany, to examine how aboveground community biomass in grasslands is affected by different components of plant diversity and thereby infer the mechanisms that may underlie positive biodiversity effects. As components of diversity we defined the number of species (1-16), number of functional groups (1-4), presence of functional groups (legumes, tall herbs, small herbs, and grasses) and proportional abundance of functional groups. Using linear models, replacement series on the level of functional groups, and additive partitioning on the level of species, we explored whether the observed biodiversity effects originated from disproportionate effects of single functional groups or species or from positive interactions between them.

Aboveground community biomass was positively related to the number of species measured across functional groups as well as to the number of functional groups measured across different levels of species richness. Furthermore, increasing the number of species within functional groups increased aboveground community biomass, indicating that species within functional groups were not redundant with respect to biomass production. A positive relationship between the number of functional groups and aboveground community biomass within a particular level of species richness suggested that complementarity was larger between species belonging to different rather than to the same functional groups. The presence of legumes or tall herbs had a strong positive impact on aboveground community biomass whereas the presence of small herbs or grasses had on average no significant effect. Two- and three-way interactions between functional group presences were weak, suggesting that their main effects were largely additive. Replacement series analyses on the level of functional groups revealed strong transgressive overyielding and relative yields $>1$, indicating facilitation. On the species level, we found strong complementarity effects that increased over time while selection effects due to disproportionate contributions of particular species decreased over time. We conclude that transgressive overyielding between functional groups and species richness effects within functional groups caused the positive biodiversity effects on aboveground community biomass in our experiment.

Key words: biodiversity; community biomass; complementarity; ecosystem functioning; functional groups; Jena Experiment; replacement series; transgressive overyielding.

\section{INTRODUCTION}

Global biodiversity is declining at a fast rate (Thomas et al. 2004, van Vuuren et al. 2006), and the predicted loss of species in the near future has the potential to

Manuscript received 15 January 2009; accepted 30 March 2009. Corresponding Editor: T. E. Huxman.

${ }^{6}$ E-mail: lisa.marquard@uwinst.unizh.ch

${ }^{7}$ Present address: Institute of Chemistry and Dynamics of the Geosphere (ICG-3), Jülich Research Centre, 52425 Jülich, Germany.

${ }^{8}$ Present address: Institute of Stochastics, FriedrichSchiller University Jena, Ernst-Abbe-Platz 2, 07743 Jena, Germany. impair ecosystem functioning (Chapin et al. 2000, Hooper et al. 2005). Experiments with manipulated diversity levels have demonstrated repeatedly that ecosystem processes are indeed positively affected by the number of and differences among species in a community (reviewed in Balvanera et al. 2006, Cardinale et al. 2006, Díaz et al. 2006). Two nonexclusive mechanisms are assumed to be the main drivers of such positive biodiversity effects (Aarssen 1997, Huston 1997, Tilman et al. 1997b, Loreau 1998): (1) a higher resource use efficiency or positive interactions within diverse mixtures (referred to as complementarity or facilitation) and (2) the presence of particular species or functional 
TABLE 1. Number of experimental plant communities at each level of species richness and functional group (FG) richness and the sown proportions for each FG.

\begin{tabular}{|c|c|c|c|c|c|c|}
\hline \multirow{2}{*}{$\begin{array}{l}\text { Species } \\
\text { richness }\end{array}$} & \multicolumn{4}{|c|}{ FG richness } & \multirow[b]{2}{*}{ Total } & \multirow[b]{2}{*}{ Sown proportions for each FG } \\
\hline & 1 & 2 & 3 & 4 & & \\
\hline 1 & 16 & & & & 16 & $0 ; 1$ \\
\hline 2 & 8 & 8 & & & 16 & $0 ; 0.5 ; 1$ \\
\hline 4 & 4 & 4 & 4 & 4 & 16 & $0 ; 0.25 ; 0.5 ; 1$ \\
\hline 8 & 4 & 4 & 4 & 4 & 16 & $0 ; 0.25 ; 0.375 ; 0.5 ; 1$ \\
\hline 16 & 2 & 4 & 4 & 4 & 14 & $0 ; 0.25 ; 0.3125 ; 0.375 ; 0.5 ; 1 \uparrow$ \\
\hline Total & 34 & 20 & 12 & 12 & 78 & \\
\hline
\end{tabular}

Note: The study was conducted on agricultural land in the floodplain of the river Saale near Jena, Germany.

$\dagger$ One only for grasses and tall herbs.

groups (FGs) in diverse mixtures that have a disproportionate effect on a property at the community level (referred to as sampling, selection, or dominance).

We used a large-scale six-year biodiversity experiment (Jena Experiment) to examine the effect of plant diversity on aboveground community biomass in grasslands and the relative contributions of complementarity (including facilitation) and selection effects (including sampling and dominance) to positive biodiversity effects.

Complementarity is assumed to be larger between species belonging to different FGs than between species belonging to the same FG (Díaz and Cabido 2001, Hooper et al. 2002). Therefore, if complementarity was the major mechanism underlying positive biodiversity effects, FG richness (number of FGs) and species richness (number of species) across FGs should more strongly affect ecosystem functioning than species richness within FGs. Analyzing the role of FG richness relative to species richness was pioneered by research using the biodiversity experiments carried out at Cedar Creek in the United States (Tilman et al. 1997a) and at the BIODEPTH sites in Europe (Hector et al. 1999, Spehn et al. 2005). Other biodiversity experiments focused on the role of FG richness relative to FG composition (Hooper and Vitousek 1997, Symstad and Tilman 2001, Hooper and Dukes 2004, Gross et al. 2007). However, in these previous experiments, it was difficult to distinguish effects of FG richness or species richness from an increased probability of including a particular FG or species in a community. It was therefore suggested that, e.g., legume presence was in fact the hidden driver of primary productivity in these experiments, not species richness or $\mathrm{FG}$ richness per se (Huston et al. 2000, Huston and McBride 2002, Mulder et al. 2002; but see van Ruijven and Berendse 2005). In contrast to previous experiments, a confounding between species richness, FG richness, and FG composition was minimized in the Jena Experiment (Roscher et al. 2004). Appendix A illustrates this improved design by contrasting exemplarily the relationship between species richness, sown proportion of legumes, and number of experimental communities in BIODEPTH and the Jena Experiment.
We applied the additive partitioning method of Loreau and Hector (2001) to quantify the contributions of complementarity (including facilitation) vs. selection (including sampling and dominance) to net effects of species diversity. This method enabled us to examine the manner in which these effects changed over time. However, to cope with the downsides of this method, such as the difficult ecological interpretation of the resulting indices (Petchey 2003, Fox 2005, Zhang and Zhang 2007) and its dependence on the performance of species in monoculture as an exclusive reference point (Adler and Bradford 2002, Fox 2006, Schmid et al. 2008), we additionally performed a replacement series analysis (De Wit 1960, Connolly 1986) to analyze whether mixtures perform better than the average of the component monocultures (overyielding) or than any of the component monocultures (transgressive overyielding; Trenbath 1974). This approach takes into account that the relative abundance of species or FGs is expected to have a significant effect on ecosystem functioning (Mulder et al. 2004, Hooper et al. 2005, Kirwan et al. 2007).

The Jena Experiment is a large-scale biodiversity experiment that was specifically designed to disentangle the effects of species richness, FG richness, presence of particular FGs, and proportional abundance (hereafter proportions) of FGs on ecosystem processes and thus assist in the elucidation of the underlying mechanisms of biodiversity effects (Roscher et al. 2004). It includes four FGs in proportions ranging from $0 \%$ to $100 \%$ at all species richness levels up to at least eight species (Table 1), allowing the separation of the effects of the presence and proportions of individual FGs from one another and from species richness effects. Furthermore, the Jena Experiment fulfills the conditions for the additive partitioning method (as all species were grown in monocultures) as well as for the replacement series approach (using proportional abundances of functional groups instead of species proportions on the $x$-axis).

Previous research has shown that biodiversity effects as well as the underlying mechanisms may change over time (Tilman et al. 2001, Hooper and Dukes 2004, Spehn et al. 2005, van Ruijven and Berendse 2005, Cardinale et al. 2007, Fargione et al. 2007, Weis et al. 
2007). Therefore, only studies comprising multiple years may result in reliable conclusions about biodiversity effects. Using data of a six-year grassland experiment, we asked the following questions: (1) What are the effects of species richness, FG richness, presence of particular FGs, and of their proportions on aboveground community biomass and which mechanisms underlie these effects? (2) What are the temporal dynamics in the effects of the different diversity components as well as in the possibly responsible mechanisms?

\section{Methods}

\section{Study area and experimental design}

The field site of the Jena Experiment encompasses $\sim 10$ ha of former agricultural land in the floodplain of the river Saale near Jena (Germany, 50 $55^{\prime} \mathrm{N}, 11^{\circ} 35^{\prime} \mathrm{E}$, $130 \mathrm{~m}$ altitude). The area around Jena is characterized by a mean annual air temperature of $9.3^{\circ} \mathrm{C}$ and a mean annual precipitation of $587 \mathrm{~mm}$ (Kluge and MüllerWestermeier 2000). The soil consists of sandy loam in the vicinity of the river that gradually changes to silty clay with increasing distance from the river.

In May 2002, 78 plant assemblages of common Central European grassland species were sown with a total of 1000 viable seeds $/ \mathrm{m}^{2}$ on plots of $20 \times 20 \mathrm{~m}$ that had been kept fallow in the year before sowing, harrowed bimonthly, and treated with glyphosate (Roundup, Monsanto, St. Louis, Missouri, USA) in July 2001. Species compositions were determined by constrained random selection from a pool of 60 species. Based on a cluster analysis of ecological and morphological traits, these 60 target species had been assigned to four FGs: 16 grasses, 12 small herbs, 20 tall herbs, and 12 legumes. In mixtures, all species were sown with equal proportions, and in plots with more than one FG all FGs were sown as evenly as possible (Roscher et al. 2004).

Table 1 shows the sown levels of species richness and FG richness as well as the sown proportions of each FG at the different diversity levels. Species richness, FG richness, and the presence of the FGs were varied as orthogonally as possible. However, there were not enough legumes and small herbs in the overall species pool to assemble them in mixtures with 16 species of the same FG. Each FG was sown in four monocultures, six two-species mixtures, 10 four-species mixtures, 10 eightspecies mixtures, and nine or 1016 -species mixtures, which resulted in the presence of each FG on 39 (legumes and small herbs) or 40 (tall herbs and grasses) of the 78 plots. For the FG richness levels of one, three, and four, all possible combinations of FGs were sown. For the level of two FGs, four out of six possible combinations were randomly selected. This procedure resulted in 13 different combinations of the four FGs sown at the different species richness levels.

Additionally, 120 monoculture plots of $3.5 \times 3.5 \mathrm{~m}$ were established (two replicates per species). All experimental plots were maintained without fertilizer application and mown twice a year (in early June and early September). Species occurring on plots where they had not been sown were removed during biannual weeding campaigns (at the beginning of the growing season and after the first mowing). Weeding was mainly done by hand; herbicides were used where target species composition allowed their application (herbicides against dicots in pure grass communities and against grasses on plots with herbs or legumes only). Empirical data showed that the application of herbicides did not affect the relationship between biodiversity and aboveground community biomass: on each of our grassland plots, a small subplot was only weeded and never treated with herbicides. These subplots showed the same biodiversity-productivity relationship as observed on the rest of the plots (Roscher et al. 2009b). The weeding treatment, however, might have decreased or increased the biodiversity-productivity relationship to some extent because low-diversity plots had to be weeded more intensively than high-diversity plots (A. Weigelt, unpublished data). Weeding could have been beneficial for the target species by creating more space and loosening the soil or it could have hampered the recruitment of target species if their seedlings were damaged. We do not know whether the potential positive or negative effects prevailed but recognize these confounding possibilities as a caveat of our study.

The field site was divided into four blocks to account for altering soil and water conditions. Mixtures and monocultures of both plot sizes were distributed in nearly equal shares across all four blocks. Weeding, mowing, and herbicide application were completed block-wise in rotating order.

\section{Sampling}

Aboveground community biomass was harvested twice per year (during peak standing biomass in late May and in late August) from 2003 to 2007 on all experimental plots (78 large plots and 120 small monocultures). This was done by clipping the vegetation at $3 \mathrm{~cm}$ above ground in four (in May 2005 and August 2007 only three) rectangles of $0.2 \times 0.5 \mathrm{~m}$ per large plot and in two rectangles of $0.2 \times 0.5 \mathrm{~m}$ per small monoculture. The locations of these rectangles were assigned prior to each harvest by random selection of coordinates within the inner area of the plots (at least 3 $\mathrm{m}$ away from the plot margins in the large plots and within the inner $2 \times 2 \mathrm{~m}$ area in the small monocultures, respectively). The positions of the rectangles within large and small plots, respectively, were identical for all plots at a particular harvest. The harvested biomass was sorted into target species (species sown at the particular plot) and dried at $70^{\circ} \mathrm{C}$ for at least $48 \mathrm{~h}$. Species not sown in a particular plot as well as detached dead plant material were removed before drying. In August 2004, the harvested biomass samples were not sorted into species (they were only sorted into legumes and 
TABLE 2. Mean number of established species ("Realized") at each level of sown species richness ("Sown") in the experimental plots in the years 2003-2007.

\begin{tabular}{crrccc}
\hline \hline & \multicolumn{5}{c}{ Realized } \\
\cline { 2 - 6 } Sown & 2003 & 2004 & 2005 & 2006 & 2007 \\
\hline 1 & 1.0 & 1.0 & $1.0(1.0)$ & $0.9(1.0)$ & $1.0(1.0)$ \\
2 & 2.0 & 2.0 & $1.9(2.0)$ & $2.0(2.0)$ & $2.0(2.0)$ \\
4 & 3.6 & 3.9 & $3.7(3.9)$ & $3.8(3.9)$ & $3.8(4.0)$ \\
8 & 7.4 & 7.4 & $6.9(7.4)$ & $6.9(7.2)$ & $7.3(7.6)$ \\
16 & 14.3 & 14.5 & $13.7(14.9)$ & $13.5(14.1)$ & $13.4(14.4)$ \\
\hline
\end{tabular}

Notes: Sample area was $9 \mathrm{~m}^{2}$. Numbers in parentheses show the mean number of established species on an area of $180 \mathrm{~m}^{2}$ in 2005-2007.

nonlegumes). Therefore, analyses requiring speciesspecific biomass data (e.g., additive partitioning) were restricted to the years 2003 and 2005-2007.

\section{Establishment of the experimental gradient}

The number of established target species was recorded twice per year in an area of $9 \mathrm{~m}^{2}$ per large plot. Additionally, the number of established target species was recorded throughout the growing season in 20052007 on an area of $\sim 180 \mathrm{~m}^{2}$ (the inner area of the plots). The strong correlation between the number of sown species and the number of established target species $\left(R^{2}\right.$ $>0.9$ in all years) verified the successful establishment of the species richness gradient (Table 2). In 2006, one large monoculture (Bellis perennis) did not produce any aboveground community biomass and we excluded this data point from all analyses.

\section{Effects of species richness and FG composition}

Aboveground biomass at the time of the harvests was calculated for each experimental community as the mean of the sampled rectangles per plot. Annual aboveground community biomass (hereafter community biomass) was calculated as the sum of the two harvests per year (data from the May harvest in 2003 were previously analyzed in Roscher et al. [2005]). We used repeated-measures analysis of variance (ANOVA) with sequential sums of squares to assess the effects of species richness and FG composition on community biomass (Schmid et al. $2002 a$ ). The model terms were fitted in two sequences to account for the remaining dependency between species richness and FG composition. In model 1, species richness was fitted prior to $\mathrm{FG}$ composition and we decomposed the variation due to FG composition into a contrast for FG richness and residual FG composition (Table 3 and Appendix D: Tables D1-D3). In model 2, FG composition was fitted prior to species richness and we decomposed the variation due to FG composition into contrasts for the presence of the particular FGs and their interactions (Table 4 and Appendix E: Tables E1E3). For the latter purpose, we substituted the single variable FG composition that contained the 13 sown combinations of the four FGs by four variables that coded for the presence of each of the four FGs and fitted their main effects (four terms) as well as two- (six terms) and three-way (two terms) interactions. For the withinplot analyses, the two- and three-way interactions were aggregated into a single term (Green and Tukey 1960). The order of the FG main effects corresponded to their effect sizes if fitted individually in a simplified yearspecific model that contained the focal FG, species richness, and the interaction between these two variables in this order (see Appendix C).

\section{Effects of FG proportions (replacement series approach)}

We categorized the 78 large plots into five classes (77 plots in 2006, because the B. perennis monoculture was excluded). Plots in which the focal FG was absent formed one class (proportional abundance of the focal $F G[P F G]=0)$ and plots in which the entire biomass was

TABLE 3. Summary of the ANOVA for aboveground community biomass from 2003 to 2007 (model 1 in Methods), using type I sums of squares.

\begin{tabular}{|c|c|c|c|c|c|c|}
\hline Source & df & SS & MS & Exp. $(\%)$ & $F$ & $P$ \\
\hline \multicolumn{7}{|l|}{ Between plots } \\
\hline Block & 3 & 1874940 & 624980 & 6 & 2.61 & 0.062 \\
\hline $\log (\mathrm{SR})$ & 1 & 6130076 & 6130076 & 18 & 25.59 & $<\mathbf{0 . 0 0 1}$ \\
\hline FG composition & 12 & 13130461 & 1094205 & 39 & 4.57 & $<0.001$ \\
\hline FG richness & 1 & 1091395 & 1091395 & 3 & 4.56 & 0.038 \\
\hline FG composition residuals & 11 & 12039066 & 1094461 & 36 & 4.57 & $<0.001$ \\
\hline $\log (\mathrm{SR}) \times$ FG composition & 12 & 667658 & 55638 & 2 & 0.23 & 0.996 \\
\hline Plot residuals & 49 & 11739473 & 239581 & 35 & & \\
\hline \multicolumn{7}{|l|}{ Within plots } \\
\hline Year & 4 & 4012604 & 1003151 & & 33.36 & $<0.001$ \\
\hline $\log (\mathrm{SR}) \times$ year & 4 & 372656 & 93164 & & 3.10 & 0.017 \\
\hline FG composition $\times$ year & 48 & 2156712 & 44931 & & 1.49 & 0.030 \\
\hline FG richness $\times$ year & 4 & 31293 & 7823 & & 0.26 & 0.903 \\
\hline FG composition residuals $\times$ year & 44 & 2125419 & 48305 & & 1.61 & 0.015 \\
\hline $\log (\mathrm{SR}) \times$ FG composition $\times$ year & 48 & 1297314 & 27027 & & 0.90 & 0.662 \\
\hline Residuals & 207 & 6224386 & 30069 & & & \\
\hline
\end{tabular}

Notes: Indented terms show the linear contrast for functional group (FG) richness and its deviation from linearity (FG composition residuals). The sum of these two terms corresponds to FG composition. Year was fitted as a five-level factor. Exp. values are the percentages of between-plot variation explained. Values in boldface are significant at $\alpha=0.05$. SR is species richness. 
TABLE 4. Summary of the ANOVA for aboveground community biomass from 2003 to 2007 (model 2 in Methods), using type I sums of squares.

\begin{tabular}{|c|c|c|c|c|c|c|}
\hline Source & $\mathrm{df}$ & SS & MS & Exp. $(\%)$ & $F$ & $P$ \\
\hline \multicolumn{7}{|l|}{ Between plots } \\
\hline Block & 3 & 1874940 & 624980 & 6 & 2.61 & 0.062 \\
\hline FG composition & 12 & 17015576 & 1417965 & 51 & 5.92 & $<0.001$ \\
\hline FG richness & 1 & 5154604 & 5154604 & 15 & 21.52 & $<0.001$ \\
\hline FG composition residuals & 11 & 11860973 & 1078270 & 35 & 4.50 & $<\mathbf{0 . 0 0 1}$ \\
\hline Main effects of particular FGs & 4 & 14637569 & 3659392 & 44 & 15.27 & $<\mathbf{0 . 0 0 1}$ \\
\hline Presence of legumes & 1 & 11721881 & 11721881 & 35 & 48.93 & $<\mathbf{0 . 0 0 1}$ \\
\hline Presence of tall herbs & 1 & 1454989 & 1454989 & 4 & 6.07 & 0.017 \\
\hline Presence of small herbs & 1 & 899072 & 899072 & 3 & 3.75 & 0.058 \\
\hline Presence of grasses & 1 & 561627 & 561627 & 2 & 2.34 & 0.132 \\
\hline Two-way interactions between FGs $\dagger$ & 6 & 1821426 & 303571 & 5 & 1.27 & 0.290 \\
\hline Three-way interactions between FGs & 2 & 556581 & 278291 & 2 & 1.16 & 0.321 \\
\hline $\log (\mathrm{SR})$ & 1 & 2244960 & 2244960 & 7 & 9.37 & 0.004 \\
\hline FG composition $\times \log (\mathrm{SR})$ & 12 & 667656 & 55638 & 2 & 0.23 & 0.996 \\
\hline Plot residuals & 49 & 11739473 & 239581 & 35 & & \\
\hline \multicolumn{7}{|l|}{ Within plots } \\
\hline Year & 4 & 4012604 & 1003151 & & 33.36 & $<\mathbf{0 . 0 0 1}$ \\
\hline FG composition $\times$ year & 48 & 2361863 & 49205 & & 2.38 & 0.002 \\
\hline FG richness $\times$ year & 4 & 215291 & 53823 & & 1.79 & 0.132 \\
\hline FG composition residuals $\times$ year & 44 & 2146572 & 48786 & & 1.62 & 0.013 \\
\hline Presence of particular FGs $\times$ year & 16 & 1504274 & 94017 & & 4.54 & $<0.001$ \\
\hline Presence of legumes $\times$ year & 4 & 709464 & 177366 & & 5.90 & $<\mathbf{0 . 0 0 1}$ \\
\hline Presence of tall herbs $\times$ year & 4 & 346729 & 86682 & & 2.88 & 0.024 \\
\hline Presence of small herbs $\times$ year & 4 & 288711 & 72178 & & 2.40 & 0.051 \\
\hline Presence of grasses $\times$ year & 4 & 159370 & 39842 & & 1.33 & 0.262 \\
\hline Residual FG composition $\times$ year & 32 & 857589 & 26800 & & 0.89 & 0.639 \\
\hline $\log (\mathrm{SR}) \times$ year & 4 & 167505 & 41876 & & 1.39 & 0.238 \\
\hline Presence of legumes $\times \log (\mathrm{SR}) \times$ year & 4 & 386332 & 96583 & & 3.21 & 0.014 \\
\hline Residual FG composition $\times \log (\mathrm{SR}) \times$ year & 44 & 910981 & 20704 & & 0.69 & 0.929 \\
\hline Residuals & 207 & 6224386 & 30069 & & & \\
\hline
\end{tabular}

Notes: Indented terms show two different sets of orthogonal contrasts for functional group (FG) composition: (1) linear contrast for FG richness and its deviation from linearity and (2) contrast for the presence of particular FGs and their interactions. In both cases the sum of contrast terms corresponds to FG composition. For the within-plots analysis, the two- and three-way interactions of FGs were aggregated into the term "residual FG composition." Year was fitted as a five-level factor. Exp. values are the percentages of between-plot variation explained. Values in boldface are significant at $\alpha=0.05$.

$\dagger$ Includes presence of legumes $\times$ tall herbs, presence of legumes $\times$ small herbs, presence of legumes $\times$ grasses, presence of tall herbs $\times$ small herbs, presence of tall herbs $\times$ grasses, and presence of small herbs $\times$ grasses.

$\ddagger$ Includes presence of legumes $\times$ tall herbs $\times$ small herbs and presence of legumes $\times$ tall herbs $\times$ grasses.

produced by the focal $\mathrm{FG}$ formed another class $(\mathrm{PFG}=$ 1). The remaining plots were sorted into those in which the focal FG contributed less than one-third $(0<\mathrm{PFG}$ $<0.33)$, between one and two-thirds $(0.33 \leq \mathrm{PFG}<$ $0.67)$, and more than two-thirds $(0.67 \leq \mathrm{PFG}<1)$ to community biomass. We considered each FG as the focal $\mathrm{FG}$ at a time and analyzed $\mathrm{FG}$ biomass and community biomass as a function of the five classes of FG proportions (Fig. 2). This analysis corresponds to the replacement series approach introduced by De Wit (1960) that was later used in plant competition experiments (Harper 1977, Connolly 1986, Jolliffe 2000).

We performed an additional analysis in which we corrected the biomass values for the species richness of the communities. To this end, we fitted a simple linear model including the logarithm of species richness as explanatory variable to the biomass data of each year. The corrected values were then calculated as the sum of the mean biomass per year and the residuals obtained by the respective year-specific model. After having accounted for species richness in this way, we performed the replacement series analyses described in the preceding paragraph.

\section{Additive partitioning}

We used the additive partitioning method of Loreau and Hector (2001) to calculate for every plot the net biodiversity effect (NE) in all years and the complementarity effect (CE) and selection effect (SE) in the years 2003 and 2005-2007. All effects were calculated using the average between the annual biomass of the two small monocultures per species as monoculture biomass of the respective species. If a species failed to establish in both monocultures at both harvests per year it was excluded from the set of target species also in corresponding mixtures in that particular year. In 2003, two two-species mixtures contained a species that had not established in monoculture and therefore NE, $\mathrm{CE}$, and SE could not be determined for these two plots in 2003. In addition, we excluded two plots in 2005 and one plot in 2006 because their transformed CE and SE fell more than three times the inter-quartile range below or above the first or third quartile, respectively. Following a conservative rule, we considered these values as outliers (Hoaglin et al. 1986). The NE, CE, and SE were analyzed with similar models as community 

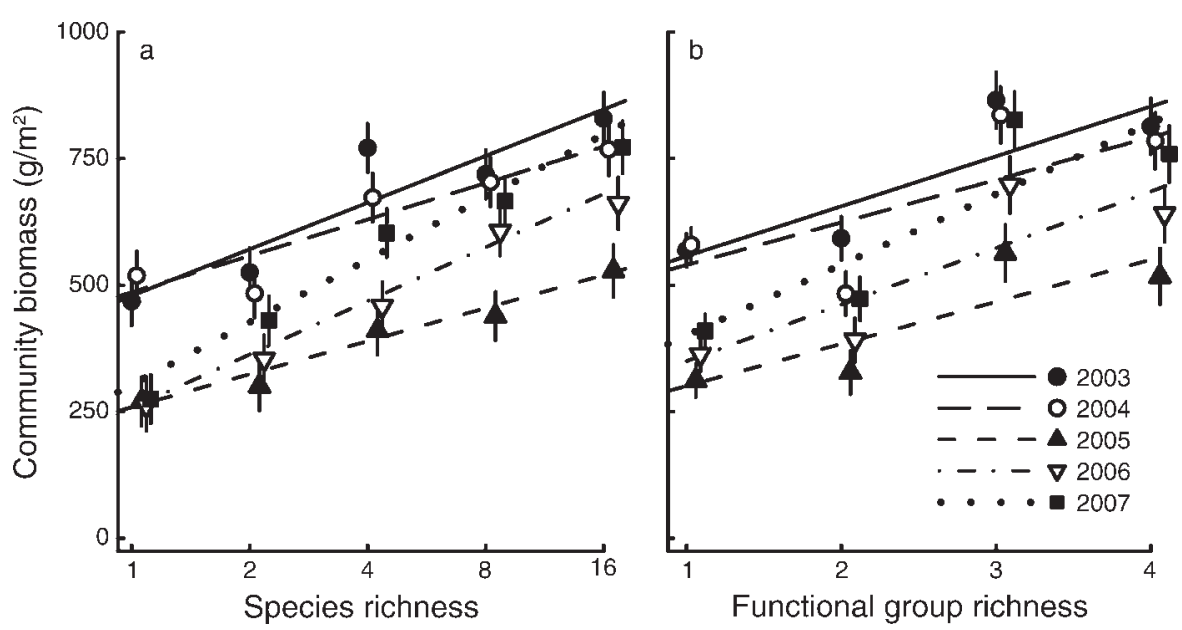

FIG. 1. Aboveground community biomass as a function of the (a) species richness (log scale) or (b) functional group richness in the years 2003-2007. Symbols represent means \pm standard error for different years. These standard errors were obtained using the square root of the residual mean square from Table 3 as an estimate for the standard deviation of the data and dividing it by the square root of the number of replicates. Fitted lines were obtained from a simplified regression model including the logarithm of species richness as a linear contrast, year as a five-level factor, and the interaction of these variables. Symbols were slightly jittered to improve visualization. The study was conducted on agricultural land in the floodplain of the river Saale near Jena, Germany.

biomass (Appendix D: Tables D1-D3 and Appendix E: Tables E1-E3). To improve the normality of the error distribution, the absolute values for $\mathrm{NE}, \mathrm{CE}$, and $\mathrm{SE}$ were square-root transformed and the result was multiplied by -1 if the original value was negative.

The recently proposed modification of the additive partitioning method by Fox (2005) yielded essentially the same results as the method of Loreau and Hector (2001): the "trait-dependent complementarity effect" (TDCE, a component of SE) was $0.56 \pm 0.94$ (mean \pm 1 standard error) and not significantly different from zero $(P=0.234)$. Therefore, we present only the results obtained by the two-fold partitioning (Loreau and Hector 2001).

\section{Robustness of species richness-community biomass relationship}

We analyzed the robustness of our results exemplarily for the relationship between sown species richness and community biomass (as assessed using model 1) by restricting its assessment to a subset of data points derived from experimental communities with a specified minimum of vegetation cover. Mean vegetation cover of the target communities was calculated as the average of two cover estimates per year, measured on an area of 9 $\mathrm{m}^{2}$ on each plot at the times of the biomass harvests. We included a data point in the analysis if it represented a target community whose mean vegetation cover exceeded a threshold varying from $>0 \%$ to $>95 \%$ cover. Each community was judged independently in every year, i.e., if a community produced a data point below the threshold in one year its remaining data points for the other years could still be included in the analysis. The full data set contained 389 data points (derived from all
78 plots in five years minus the $B$. perennis monoculture in 2006).

This analysis showed that the positive species richness-community biomass relationship (as presented in Results and Fig. 1) was significant $(P<0.05)$ until less than one-third of all plots were analyzed (with a vegetation cover $>92 \%$; see Appendix B). Only a few plots had a cover of $<50 \%$, and excluding these from the analysis had almost no effect on the relationship between species richness and community biomass. Thresholds of $\sim 70 \%$ vegetation cover resulted in lower values for $R^{2}$, but the strength of the relationship increased again if the threshold was set higher. We think this result justifies the inclusion of all data points derived from communities with a vegetation cover $>0$ in the analyses presented here.

We used the statistical software R (version 2.6.2; R Foundation for Statistical Computing, Vienna, Austria) for all calculations and statistical analyses.

\section{RESUlts}

\section{Effects of species richness and FG composition}

We found a positive linear relationship between the logarithm of species richness and community biomass over the entire observation period from 2003 to 2007 (Fig. 1a). Mean community biomass per square meter declined from 2003 to 2005 but then recovered again (2006 and 2007). The strength of the relationship between the logarithm of species richness and community biomass varied significantly between the years (term " $\log (\mathrm{SR}) \times$ year" in Table 3 ; level of significance $\alpha=$ 0.05 ) and was stronger in the years 2006 and 2007 than in the earlier years of our study (Fig. 1a). On average, doubling the number of species increased community biomass by $91 \mathrm{~g} / \mathrm{m}^{2}$. Species richness explained $18 \%$ of 

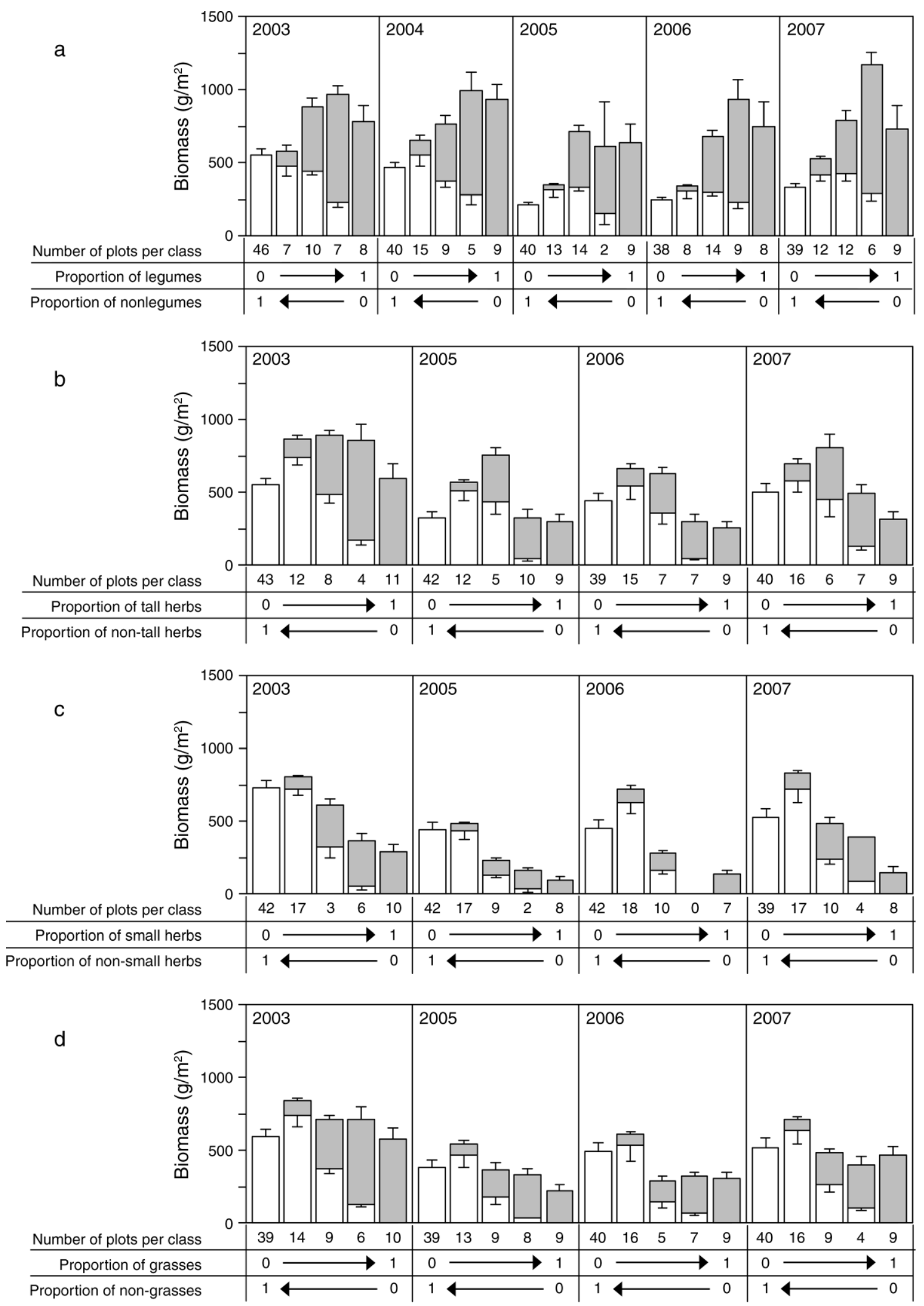
the variation in community biomass between the plots when fitted prior to FG composition (Table 3). Within a given level of species richness, FG composition strongly affected community biomass. A significant proportion of this effect was caused by increasing the number of FGs ("FG richness" in Table 3), suggesting that species were more complementary among FGs than within FGs. In addition, the particular combination of FGs played an important role independently of their number ("FG composition residuals" in Table 3). The effect of FG composition changed significantly over time.

When we did not control for differences in species richness, FG composition explained $51 \%$ of the variation in community biomass among plots (Table 4). Functional group richness was responsible for almost one-third of this proportion and the relationship between FG richness and community biomass was temporally stable (Table 4, Fig. 1b). On average, adding one FG to a community increased community biomass by $103 \mathrm{~g} / \mathrm{m}^{2}$. The biomass of communities containing the same number of FGs was significantly affected by the identity of the FGs present ("FG composition residuals" in Table 4). In particular, legumes and tall herbs had significant positive effects. The effect of legumes on community biomass changed over time and was especially strong in 2006 (Table 4; see Appendix C). In some years, legumes also affected the strength of the relationship between species richness and community biomass ("Presence of legumes $\times \log (\mathrm{SR}) \times$ year" in Table 4). The effect of tall herbs was strongest in 2003 and not any longer observed in 2006 and 2007 (Table 4; Appendix C). Small herbs showed a tendency to reduce community biomass, but this effect was only significant in 2004 (Table 4; Appendix C). Grasses slightly enhanced community biomass in 2003 (Appendix C), but averaged over all years, their effect was not significant (Table 4). The effects of the presence of particular FGs and of species richness were additive as none of the corresponding interactions in model 2 or in the analyses for Appendix $\mathrm{C}$ were significant. These interactions were therefore subsumed under the term "FG composition $\times \log (\mathrm{SR})$ " in Table 4 and not displayed in Appendix C. Among communities of equal FG composition, those with more species produced more biomass (" $\log (\mathrm{SR})$ " in Table 4).

\section{Effects of FG proportions (replacement series approach)}

If mixed with species from other FGs, any of our four FGs could enhance the absolute biomass of a commu- nity beyond the biomass of communities where its proportion was either $0 \%$ or $100 \%$ (i.e., some inner bars were always higher than outer bars in Fig. 2). Such transgressive overyielding (Trenbath 1974) occurred for all four FGs in all years at least at one and often at several of the mixing ratios. When the focal $\mathrm{FG}$ had an abundance of $<33 \%$, the sum of the biomass of the remaining FGs (white part of bars in Fig. 2) was nearly always higher than the total biomass of these FGs alone (with the exceptions of legumes in 2003 and small herbs in 2003 and 2005). In other words, the relative yield (i.e., biomass of a species in mixture divided by its biomass in monoculture; see De Wit 1960, Harper 1977, Jolliffe 2000) of the non-focal FGs was $>1$, indicating facilitation of the remaining FGs by the focal FG. The relative yield of the focal FG (gray part of the bars in Fig. 2), was also often $>1$ if the proportion of the focal FG was larger than $67 \%$ (legumes in 2007, tall herbs in 2003 and 2007, small herbs in 2003, 2005, and 2007, and grasses in 2003 and 2005). This indicated that the focal FG also benefited from facilitation. The degree of transgressive overyielding between FGs was relatively constant during the observation period.

Similar results were obtained after having accounted for the number of species within the communities (not shown).

\section{Additive partitioning}

Averaged over all species richness levels and all years, the net biodiversity effect (NE) and its components $\mathrm{CE}$ and SE were significantly positive $\left(192 \pm 17 \mathrm{~g} / \mathrm{m}^{2}, 135 \pm\right.$ $17 \mathrm{~g} / \mathrm{m}^{2}$, and $\left.18 \pm 7 \mathrm{~g} / \mathrm{m}^{2}\right)$, but all three effects changed over time (see Appendix D: Tables D1-D3 and Appendix E: E1-E3). While NE decreased until 2005 and increased thereafter, CE increased and SE decreased continuously over time (Fig. 3). The NE and CE were positively related to species richness in communities irrespective of whether the communities were of the same or of different FG compositions (for NE, Appendix D: Table D1 and Appendix E: Table E1; for CE, Appendix D: Table D2 and Appendix E: Table E2). When fitted prior to species richness, FG composition accounted for more than half of the variation in NE and CE among plots (Appendix E: Tables E1 and E2). Functional group richness was responsible for more than one-third (NE) or more than half (CE) of this amount. Replacing the FG richness contrast with contrasts for the presence of particular FGs and their interactions revealed a strong positive impact of legumes

FIG. 2. Replacement series diagrams for aboveground community biomass. The $x$-axis represents classes of proportions of the focal functional group (FG; increasing from left to right) and the non-focal FGs (decreasing from left to right) based on relative abundance (in terms of biomass). The $y$-axis represents absolute aboveground biomass of the entire community, partitioned into focal FG (gray) and non-focal FGs (white). Each bar represents the mean and standard error of the corresponding proportion class. The limits of the five proportion classes, using the proportional abundances of the focal FG (PFG), were: $P F G=0 ; 0<P F G$ $<0.33 ; 0.33 \leq \mathrm{PFG}<0.67 ; 0.67 \leq \mathrm{PFG}<1$; and PFG $=1$. We considered each FG as the focal FG at a time: (a) legumes, (b) tall herbs, (c) small herbs, and (d) grasses. Their effects are shown for the years 2003-2007. In 2004, only legumes were separated from nonlegumes during the biomass harvest. 


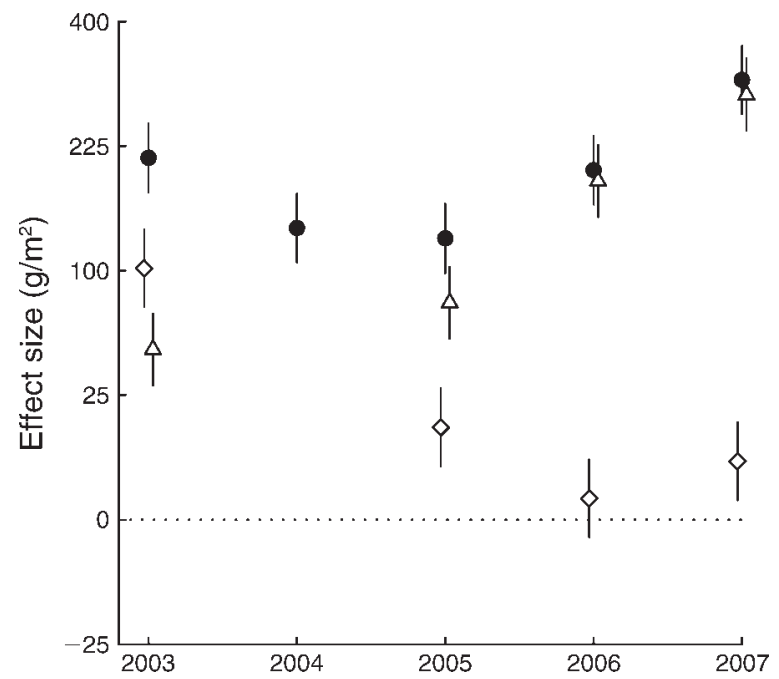

FIG. 3. Net biodiversity effect (NE, circles), complementarity effect (CE, triangles) and selection effect (SE, diamonds) over time. Symbols represent means \pm standard error. Note the square-root scale of the $y$-axis. For 2004, CE and SE could not be estimated because community biomass was not separated to species. Symbols were slightly jittered to improve visualization.

and a positive effect of tall herbs on NE and CE. The effect of legumes on $\mathrm{NE}$ and $\mathrm{CE}$ occurred during the entire observation period (Appendix E: Tables E1 and E2). The positive effect of tall herbs on NE decreased significantly over time (Appendix E: Table E1), whereas the positive effect of tall herbs on $\mathrm{CE}$ remained (Appendix E: Table E2). The SE was not affected by species richness and only marginally affected by FG composition in some years. An initially positive effect of tall herbs on SE decreased significantly over time (Appendix D: Table D3 and Appendix E: Table E3).

\section{Discussion}

\section{Effects of diversity components on community biomass}

We identified strong positive effects of the two richness components (species richness and FG richness) and of the presence of two particular FGs, legumes and tall herbs, on community biomass, NE, and CE. It is often assumed that effects of species richness should be weaker than effects of FG richness (Hooper et al. 2005, Jiang et al. 2007). However, this was not supported by our results. In previous experiments, the two richness components were usually more strongly confounded with FG composition than in the Jena Experiment and effects of species richness and especially of FG richness could therefore be interpreted as effects caused by an increased probability for the inclusion of legumes at higher richness levels (Spehn et al. 2005). In our experiment, this confounding was minimized (see Appendix A), and species richness remained highly significant when we corrected for all effects that were potentially due to the presence of particular FGs or their interactions. Thus, our results demonstrate that increasing species richness without changing FG composition has a positive effect on community biomass and support the conclusions of Reich et al. (2004) and Lanta and Lepš (2007) in that species within FGs are not completely redundant in their functions. Nevertheless, if the effect of species richness was measured across different FG compositions, its effect was about three times as large as within a particular combination of FGs (compare Table 3 with Table 4). This suggests that the greater differences between species across as opposed to within FGs resulted in increased complementarity and positive species richness effects when different FGs were mixed (Tilman et al. 1997b, Loreau 1998).

Of our four FGs, legumes had the strongest and generally positive effects on community biomass and NE. This was mainly due to positive interactions between legumes and species belonging to other FGs (as seen in Fig. 2 and in the positive effect of legume presence on CE; Appendix E: Table E2). Disproportionate contributions of legume biomass to community biomass were less important (no significant effect of legume presence on SE; Appendix E: Table E3). Strong positive effects of legumes on community biomass have been found in other biodiversity experiments (Tilman et al. 1997a, 2001, Hector et al. 1999, Mulder et al. 2002, Hille Ris Lambers et al. 2004, Spehn et al. 2005), which may be explained by the improved nitrogen availability on legume-containing plots promoting complementary resource use or facilitation (Spehn et al. 2002, Fridley 2003, Dimitrakopoulos and Schmid 2004, Oelmann et al. 2007b, Temperton et al. 2007).

Tall herbs increased community biomass and NE partly via complementarity (as seen in Fig. 2 and in the positive effect of tall herb presence on CE; Appendix E: Table E2) and partly via disproportionate contributions of tall herb biomass to community biomass (as seen in the positive effect of tall herb presence on SE; Appendix E: Table E3). Tall herbs were generally characterized by a medium or tall stature but were rather variable with regard to other traits (Roscher et al. 2004). While their positive effect on SE was likely related to their tall growth, their contribution to community biomass via complementarity could have been the result of various mechanisms that await further clarification.

Grasses and small herbs had minor effects on community biomass. While the minor effects of small herbs on community biomass were not surprising, we had expected a stronger impact of grasses as they had pronounced effects on other ecosystem functions in the Jena Experiment: grasses decreased individual plant performance (Scherber et al. 2006, Mwangi et al. 2007), increased invasion resistance (Roscher et al. 2009a), changed nitrogen and phosphorus fluxes (Oelmann et al. 2007a, b), and affected the soil fauna (Milcu et al. 2006).

The replacement series analyses showed that any of our FGs could generate a positive biodiversity effect (see Fig. 2). In agreement with our remaining analyses we 
found the largest effects for legumes and tall herbs. However, small herbs and grasses generated positive effects as well if their proportions were low. Several mechanisms could be the drivers of such positive interactions not necessarily involving legumes, e.g., increased light and nutrient use efficiency, favorable alteration of microclimatic conditions, or beneficial changes in soil properties (Callaway 1997, 2007, van Ruijven and Berendse 2005, Daßler et al. 2008).

If the mixing ratio between the focal FG and the nonfocal FGs fell within a particular range, community biomass was higher than if the focal FG or the non-focal FGs grew alone. Therefore, mixed assemblages (containing the focal FG as well as non-focal FGs) could transgressively overyield pure assemblages (containing only the focal FG or the non-focal FGs). Transgressive overyielding is generally regarded as a conservative test for complementarity because the sampling effect alone cannot result in mixtures producing more biomass than any of the component monocultures (Huston et al. 2000, Tilman et al. 2001). We could further rule out sampling as the main mechanism for increasing community biomass in all cases in which the relative yield was $>1$. Here, the beneficial effect of mixing different FGs was not only apparent for the total community but also for the respective fraction illustrating the possibility that community biomass is enhanced via increasing diversity even if the biomass of the added species is not considered for the outcome.

Relative yields $>1$ are particularly informative because they reveal that facilitation and not only reduced resource competition (complementarity in the strict sense) contributed to the positive biodiversity effect (Schmid et al. 2002b). So far, only a few experimental studies have been reported that differentiated between these two mechanisms (Caldeira et al. 2001, Mulder et al. 2001; see also the discussion of this issue in Callaway [2007]). To our knowledge, relative yields $>1$ were only once demonstrated in a similar way in mixtures of two species (Weiner 1980) but never in mixtures of multiple FGs.

Transgressive overyielding is thought to be rather the exception than the rule (Cardinale et al. 2006, but see Kirwan et al. 2007). However, it has been shown that the calculation of a transgressive overyielding index involves a sample bias (Schmid et al. 2008) of which our results are unaffected. We showed that transgressive overyielding occurred for all four focal FGs in all years. This remarkable consistency suggests that transgressive overyielding may be more common than previously estimated.

The lack of significant two- and three-way interactions between the presences of the individual FGs indicates that the FGs exerted their effects on community biomass without compromising the effect of the other FGs present. Mixing legumes and tall herbs therefore led to a double positive effect. Similarly, the additiveness of the effects of the presence of particular
FGs and of species richness as well as the fact that any of our FGs could generate transgressive overyielding if present at a particular proportion demonstrates that the combined contributions of different FGs in many cases increased community biomass even further than the presence of a single FG.

\section{Temporal dynamics in biodiversity effects}

In the past, analyses of biodiversity-ecosystem functioning relationships that used data of multiple years produced ambiguous results. The effect of biodiversity was observed to either increase (Tilman et al. 2001, Mulder et al. 2002, Hooper and Dukes 2004, Spehn et al. 2005, van Ruijven and Berendse 2005, Fargione et al. 2007) or decrease over time (Bell et al. 2005) or to show complex temporal dynamics (Weis et al. 2007). In our experiment, the effects of species richness and $\mathrm{FG}$ richness on community biomass as well as NE were positive throughout the entire observation period and the effect of species richness increased with time. We conclude that biodiversity effects are not a transient phenomenon only found during plant community establishment and may instead increase over time.

The increasing CE but decreasing SE suggested that, over time, positive interactions between multiple species or FGs became relatively more important for the generation of biodiversity effects than disproportionate effects of single species or FGs (see Fig. 3). A decrease in the average SE can have several reasons: either species in mixture increasingly approach their expected abundances or the variance between the monocultures of the component species declines over time or the number of negative values for SE increases in the sample. While the first two of these alternatives are incompatible with our observation that the variance in SE increased between 2003 and 2005, the third explanation seems plausible as the number of plots with a negative SE indeed increased during that period (not shown).

Negative selection effects have been reported from several other studies (Špaèková and Lepš 2001, Hooper and Dukes 2004, Cardinale et al. 2007, Jiang 2007) and result either from species with higher-than-average biomass in monoculture that perform relatively poorly in mixture (Hooper and Dukes 2004) or from species with a lower-than-average biomass in monoculture that are more abundant in mixture than expected (Cardinale et al. 2007). As we observed a strong increase in CE, the likely cause for a higher number of negative SE values was the increasing promotion of the growth of species in mixture that performed poorly in monoculture. This conclusion supports previous findings (Hille Ris Lambers et al. 2004, Fargione et al. 2007) in that the performance of a species in monoculture does not necessarily predict its competitive abilities in mixtures and highlights once more that effect sizes calculated by the additive partitioning method according to Loreau and Hector (2001) need to be interpreted with care. 
In summary, the continuously positive effects of species richness and FG richness and the positive values for NE demonstrate that the biomass of mixtures exceeded their expected yields based on their component monocultures' performances in all years. In agreement with a recent meta-analysis showing that biodiversity effects resulted most often from a combination of multispecies complementarity and species-specific selection effects (Cardinale et al. 2007), we could show that both mechanisms played a role in the Jena Experiment. Nevertheless, the evidence for facilitation and transgressive overyielding was strong, and the strength and relative importance of complementarity increased over time.

\section{Conclusions}

Aboveground biomass production in plant communities is affected by several components of plant biodiversity such as species richness, FG richness, presence of particular FGs, and their proportions. Therefore, the loss of species from ecosystems is likely to result in reductions of ecosystem functions, irrespective of the nature of the diversity component that is lost. Species within FGs are not necessarily redundant with regard to community biomass and effects of different diversity components may be additive. Mixing species of different FGs can lead to strong transgressive overyielding and additive and facilitative effects between species, and FGs may increase over time. We suggest that methods presently not commonly used in biodiversity research, such as the replacement series analysis, and the consideration of diversity components other than species richness can broaden our understanding of the consequences of changing biodiversity.

\section{ACKNOWLEDGMENTS}

We thank the gardeners of the Jena Experiment and many field assistants for maintaining the plots and handling numerous biomass samples. We are grateful to A. Fergus, M. Gubsch, A. Lipowsky, J. Petermann, T. Rottstock, and A. Schmidtke for helping with the fieldwork and for supplementing the realized richness data in 2005. The comments of three anonymous reviewers greatly improved the paper. The Jena Experiment is funded by the German Research Foundation (FOR 456) and supported by the Friedrich Schiller University of Jena and the Max Planck Institute for Biogeochemistry, Jena. Additional support was provided by the Swiss National Science Foundation (grant number 31-65224-01 to B. Schmid).

\section{Literature Cited}

Aarssen, L. W. 1997. High productivity in grassland ecosystems: Effected by species diversity or productive species? Oikos 80:183-184.

Adler, P. B., and J. B. Bradford. 2002. Compensation: an alternative method for analyzing diversity-productivity experiments. Oikos 96:411-420.

Balvanera, P., A. B. Pfisterer, N. Buchmann, J.-S. He, T. Nakashizuka, D. Raffaelli, and B. Schmid. 2006. Quantifying the evidence for biodiversity effects on ecosystem functioning and services. Ecology Letters 9:1-11.

Bell, T., J. A. Newman, B. W. Silverman, S. L. Turner, and A. K. Lilley. 2005. The contribution of species richness and composition to bacterial services. Nature 436:1157-1160.
Caldeira, M. C., R. J. Ryel, J. H. Lawton, and J. S. Pereira. 2001. Mechanisms of positive biodiversity-production relationships: insights provided by $\delta^{13} \mathrm{C}$ analysis in experimental Mediterranean grassland plots. Ecology Letters 4:439-443.

Callaway, R. M. 1997. Positive interactions in plant communities and the individualistic-continuum concept. Oecologia 112:143-149.

Callaway, R. M. 2007. Positive interactions and interdependence in plant communities. Springer, Dordrecht, The Netherlands.

Cardinale, B. J., D. S. Srivastava, J. E. Duffy, J. P. Wright, A. L. Downing, M. Sankaran, and C. Jouseau. 2006. Effects of biodiversity on the functioning of trophic groups and ecosystems. Nature 443:989-992.

Cardinale, B. J., J. P. Wright, M. W. Cadotte, I. T. Carroll, A. Hector, D. S. Srivastava, M. Loreau, and J. J. Weis. 2007. Impacts of plant diversity on biomass production increase through time because of species complementarity. Proceedings of the National Academy of Sciences 104:18123-18128.

Chapin, F. S., III, E. S. Zavaleta, V. T. Eviner, R. L. Naylor, P. M. Vitousek, H. L. Reynolds, D. U. Hooper, S. Lavorel, O. E. Sala, S. E. Hobbie, M. C. Mack, and S. Díaz. 2000. Consequences of changing biodiversity. Nature 405:234-242.

Connolly, J. 1986. On difficulties with replacement-series methodology in mixture experiments. Journal of Applied Ecology 23:125-137.

Daßler, A., C. Roscher, V. M. Temperton, J. Schumacher, and E.-D. Schulze. 2008. Adaptive survival mechanisms and growth limitations of small-stature herb species across a plant diversity gradient. Plant Biology 10:573-587.

De Wit, C. T. 1960. On competition. Verslagen Landbouwkundige Onderzoekingen $66: 1-82$.

Díaz, S., and M. Cabido. 2001. Vive la différence: plant functional diversity matters to ecosystem processes. Trends in Ecology and Evolution 16:646-655.

Díaz, S., J. Fargione, F. S. Chapin, III, and D. Tilman. 2006. Biodiversity loss threatens human well-being. PLoS Biology 4:1300-1305.

Dimitrakopoulos, P. G., and B. Schmid. 2004. Biodiversity effects increase linearly with biotope space. Ecology Letters 7:574-583.

Fargione, J., D. Tilman, R. Dybzinski, J. Hille Ris Lambers, C. Clark, W. S. Harpole, J. M. H. Knops, P. B. Reich, and M. Loreau. 2007. From selection to complementarity: shifts in the causes of biodiversity-productivity relationships in a long-term biodiversity experiment. Proceedings of the Royal Society B 274:871-876.

Fox, J. W. 2005. Interpreting the 'selection effect' of biodiversity on ecosystem function. Ecology Letters 8:846-856.

Fox, J. W. 2006. Using the Price Equation to partition the effects of biodiversity loss on ecosystem function. Ecology 87: 2687-2696.

Fridley, J. D. 2003. Diversity effects on production in different light and fertility environments: an experiment with communities of annual plants. Journal of Ecology 91:396-406.

Green, B. F., and J. W. Tukey. 1960. Complex analyses of variance: general problems. Psychometrika 25:127-152.

Gross, N., K. N. Suding, S. Lavorel, and C. Roumet. 2007. Complementarity as a mechanism of coexistence between functional groups of grasses. Journal of Ecology 95:12961305.

Harper, J. L. 1977. Population biology of plants. Academic Press, London, UK.

Hector, A., et al. 1999. Plant diversity and productivity experiments in European grasslands. Science 286:11231127.

Hille Ris Lambers, J., S. W. Harpole, D. Tilman, J. Knops, and P. B. Reich. 2004. Mechanisms responsible for the positive diversity-productivity relationship in Minnesota grasslands. Ecology Letters 7:661-668. 
Hoaglin, D. C., B. Iglewicz, and J. W. Tukey. 1986. Performance of some resistant rules for outlier labeling. Journal of the American Statistical Association 81:991-999.

Hooper, D. U., and J. S. Dukes. 2004. Overyielding among plant functional groups in a long-term experiment. Ecology Letters 7:95-105.

Hooper, D. U., and P. M. Vitousek. 1997. The effects of plant composition and diversity on ecosystem processes. Science 277:1302-1305.

Hooper, D. U., et al. 2002. Species diversity, functional diversity, and ecosystem functioning. Pages 195-208 in M. Loreau, S. Naeem, and P. Inchausti, editors. Biodiversity and ecosystem functioning: synthesis and perspectives. Oxford University Press, New York, New York, USA.

Hooper, D. U., et al. 2005. Effects of biodiversity on ecosystem functioning: a consensus of current knowledge. Ecological Monographs 75:3-35.

Huston, M. A. 1997. Hidden treatments in ecological experiments: re-evaluating the ecosystem function of biodiversity. Oecologia 110:449-460.

Huston, M. A., L. W. Aarssen, M. P. Austin, B. S. Cade, J. D. Fridley, E. Garnier, J. P. Grime, J. Hodgson, W. K. Lauenroth, K. Thompson, J. H. Vandermeer, and D. A. Wardle. 2000. No consistent effect of plant diversity on productivity. Science 289:1255a.

Huston, M. A., and A. C. McBride. 2002. Evaluating the relative strengths of biotic versus abiotic controls on ecosystem processes. Pages 47-60 in M. Loreau, S. Naeem, and P. Inchausti, editors. Biodiversity and ecosystem functioning: synthesis and perspectives. Oxford University Press, Oxford, UK.

Jiang, L. 2007. Negative selection effects suppress relationships between bacterial diversity and ecosystem functioning. Ecology 88:1075-1085.

Jiang, X. L., W. G. Zhang, and G. Wang. 2007. Effects of different components of diversity on productivity in artificial plant communities. Ecological Research 22:629-634.

Jolliffe, P. A. 2000. The replacement series. Journal of Ecology 88:371-385.

Kirwan, L., et al. 2007. Evenness drives consistent diversity effects in intensive grassland systems across 28 European sites. Journal of Ecology 95:530-539.

Kluge, G., and G. Müller-Westermeier. 2000. Das Klima ausgewählter Orte der Bundesrepublik Deutschland: Jena. Deutscher Wetterdienst, Offenbach, Germany.

Lanta, V., and J. Lepš. 2007. Effects of species and functional group richness on production in two fertility environments: an experiment with communities of perennial plants. Acta Oecologica 32:93-103.

Loreau, M. 1998. Biodiversity and ecosystem functioning: a mechanistic model. Proceedings of the National Academy of Sciences (USA) 95:5632-5636.

Loreau, M., and A. Hector. 2001. Partitioning selection and complementarity in biodiversity experiments. Nature $412: 72$ 76.

Milcu, A., S. Partsch, R. Langel, and S. Scheu. 2006. The response of decomposers (earthworms, springtails and microorganisms) to variations in species and functional group diversity of plants. Oikos 112:513-524.

Mulder, C. P. H., E. Bazeley-White, P. G. Dimitrakopoulos, A. Hector, M. Scherer-Lorenzen, and B. Schmid. 2004. Species evenness and productivity in experimental plant communities. Oikos 107:50-63.

Mulder, C. P. H., A. Jumpponen, P. Högberg, and K. HussDanell. 2002. How plant diversity and legumes affect nitrogen dynamics in experimental grassland communities. Oecologia 133:412-421.

Mulder, C. P. H., D. D. Uliassi, and D. F. Doak. 2001. Physical stress and diversity-productivity relationships: the role of positive interactions. Proceedings of the National Academy of Sciences (USA) 98:6704-6708.
Mwangi, P. N., M. Schmitz, C. Scherber, C. Roscher, J. Schumacher, M. Scherer-Lorenzen, W. W. Weisser, and B. Schmid. 2007. Niche pre-emption increases with species richness in experimental plant communities. Journal of Ecology 95:65-78.

Oelmann, Y., Y. Kreutziger, V. M. Temperton, N. Buchmann, C. Roscher, J. Schumacher, E. D. Schulze, W. W. Weisser, and W. Wilcke. 2007a. Nitrogen and phosphorus budgets in experimental grasslands of variable diversity. Journal of Environmental Quality 36:396-407.

Oelmann, Y., W. Wilcke, V. M. Temperton, N. Buchmann, C. Roscher, J. Schumacher, E. D. Schulze, and W. W. Weisser. 2007b. Soil and plant nitrogen pools as related to plant diversity in an experimental grassland. Soil Science Society of America Journal 71:720-729.

Petchey, O. L. 2003. Integrating methods that investigate how complementarity influences ecosystem functioning. Oikos 101:323-330.

Reich, P. B., D. Tilman, S. Naeem, D. S. Ellsworth, J. Knops, J. Craine, D. Wedin, and J. Trost. 2004. Species and functional group diversity independently influence biomass accumulation and its response to $\mathrm{CO}_{2}$ and $\mathrm{N}$. Proceedings of the National Academy of Sciences (USA) 101:10101-10106.

Roscher, C., H. Bessler, Y. Oelmann, C. Engels, W. Wilcke, and E.-D. Schulze. 2009a. Resources, recruitment limitation and invader species identity determine pattern of spontaneous invasion in experimental grasslands. Journal of Ecology 97:32-47.

Roscher, C., J. Schumacher, J. Baade, W. Wilcke, G. Gleixner, W. W. Weisser, B. Schmid, and E.-D. Schulze. 2004. The role of biodiversity for element cycling and trophic interactions: an experimental approach in a grassland community. Basic and Applied Ecology 5:107-121.

Roscher, C., V. M. Temperton, N. Buchmann, and E.-D. Schulze. 2009b. Community assembly and biomass production in regularly and never weeded experimental grasslands. Acta Oecologica 35:206-217.

Roscher, C., V. M. Temperton, M. Scherer-Lorenzen, M. Schmitz, J. Schumacher, B. Schmid, N. Buchmann, W. W. Weisser, and E.-D. Schulze. 2005. Overyielding in experimental grassland communities - irrespective of species pool or spatial scale. Ecology Letters 8:419-429.

Scherber, C., A. Milcu, S. Partsch, S. Scheu, and W. W. Weisser. 2006. The effects of plant diversity and insect herbivory on performance of individual plant species in experimental grassland. Journal of Ecology 94:922-931.

Schmid, B., A. Hector, M. Huston, P. Inchausti, I. Nijs, P. Leadley, and D. Tilman. 2002a. The design and analysis of biodiversity experiments. Pages 61-75 in M. Loreau, S. Naeem, and P. Inchausti, editors. Biodiversity and ecosystem functioning: synthesis and perspectives. Oxford University Press, New York, New York, USA.

Schmid, B., A. Hector, P. Saha, and M. Loreau. 2008. Biodiversity effects and transgressive overyielding. Journal of Plant Ecology 1:95-102.

Schmid, B., J. Joshi, and F. Schläpfer. 2002b. Empirical evidence for biodiversity-ecosystem functioning relationships. Pages $120-150$ in A. P. Kinzig, D. Tilman, and S. W. Pacala, editors. Functional consequences of biodiversity: experimental progress and theoretical extensions. Princeton University Press, Princeton, New Jersey, USA.

Špaèková, I., and J. Lepš. 2001. Procedure for separating the selection effect from other effects in diversity-productivity relationship. Ecology Letters 4:585-594.

Spehn, E. M., et al. 2002. The role of legumes as a component of biodiversity in a cross-European study of grassland biomass nitrogen. Oikos 98:205-218.

Spehn, E. M., et al. 2005. Ecosystem effects of biodiversity manipulations in European grasslands. Ecological Monographs 75:37-63. 
Symstad, A. J., and D. Tilman. 2001. Diversity loss, recruitment limitation, and ecosystem functioning: lessons learned from a removal experiment. Oikos 92:424-435.

Temperton, V. M., P. N. Mwangi, M. Scherer-Lorenzen, B. Schmid, and N. Buchmann. 2007. Positive interactions between nitrogen-fixing legumes and four different neighbouring species in a biodiversity experiment. Oecologia 151: 190-205.

Thomas, C. D., et al. 2004. Extinction risk from climate change. Nature 427:145-148.

Tilman, D., J. Knops, D. Wedin, P. Reich, M. Ritchie, and E. Siemann. 1997a. The influence of functional diversity and composition on ecosystem processes. Science 277:1300-1302.

Tilman, D., C. L. Lehman, and K. T. Thomson. 1997b. Plant diversity and ecosystem productivity: theoretical considerations. Proceedings of the National Academy of Sciences (USA) 94:1857-1861.

Tilman, D., P. B. Reich, J. Knops, D. Wedin, T. Mielke, and C. Lehman. 2001. Diversity and productivity in a long-term grassland experiment. Science 294:843-845.
Trenbath, B. R. 1974. Biomass productivity of mixtures. Advances in Agronomy 26:177-210.

van Ruijven, J., and F. Berendse. 2005. Diversity-productivity relationships: initial effects, long-term patterns, and underlying mechanisms. Proceedings of the National Academy of Sciences (USA) 102:695-700.

Van Vuuren, D. P., O. E. Sala, and H. M. Pereira. 2006. The future of vascular plant diversity under four global scenarios. Ecology and Society 11:25.

Weiner, J. 1980. The effects of plant density, species proportion and potassium-phosphorus fertilization on interference between Trifolium incarnatum and Lolium multiflorum with limited nitrogen supply. Journal of Ecology 68:969-979.

Weis, J. J., B. J. Cardinale, K. J. Forshay, and A. R. Ives. 2007. Effects of species diversity on community biomass production change over the course of succession. Ecology 88:929939.

Zhang, Q. G., and D. Y. Zhang. 2007. Consequences of individual species loss in biodiversity experiments: an essentiality index. Acta Oecologica 32:236-242.

\section{APPENDIX A}

The differences between the design of previous biodiversity experiments, exemplified by the European BIODEPTH Experiment, and the Jena Experiment (Ecological Archives E090-234-A1).

\section{APPENDIX B}

The effect of selecting a subsample of data points on the strength of the relationship between the logarithm of species richness and aboveground community biomass (Ecological Archives E090-234-A2).

\section{APPENDIX C}

The effects of presence and absence of the functional groups legumes, tall herbs, small herbs, and grasses on aboveground community biomass over the species richness gradient from 2003 to 2007 (Ecological Archives E090-234-A3).

\section{APPENDIX D}

Three tables summarizing the ANOVAs for the net effect from 2003 to 2007 and for the complementarity effect and selection effect in 2003 and 2005-2007, using a statistical model in which species richness was fitted prior to functional group composition (Ecological Archives E090-234-A5).

\section{APPENDIX E}

Three tables summarizing the ANOVAs for the net effect from 2003 to 2007 and for the complementarity effect and selection effect in 2003 and 2005-2007, using a statistical model in which functional group composition was fitted prior to species richness (Ecological Archives E090-234-A4). 